\title{
Face Mask-Associated Ocular Irritation and Dryness
}

\author{
Majid Moshirfar (D) - William B. West Jr. · Douglas P. Marx
}

Received: May 20, 2020 / Published online: July 15, 2020

(c) The Author(s) 2020

Keywords: Coronavirus; COVID-19; Dry eye; Exposure keratopathy; Face mask; Keratitis;

Digital Features To view digital features for this article go to https://doi.org/10.6084/m9.figshare.12562595.

M. Moshirfar ( $₫)$

Hoopes Vision Research Center, Draper, UT, USA

e-mail: Cornea2020@me.com

M. Moshirfar · D. P. Marx

Department of Ophthalmology and Visual Sciences, John A. Moran Eye Center, University of Utah, Salt Lake City, UT, USA

M. Moshirfar

Utah Lions Eye Bank, Murray, UT, USA

W. B. West Jr.

The University of Utah School of Medicine, Salt Lake City, UT, USA

Keratopathy; Mask; Personal protective equipment; PPE

\section{Key Summary Points}

Widespread use of face masks, while essential for the prevention of novel coronavirus transmission, may cause ocular dryness and irritation.

Irritation of the ocular surface associated with mask use raises concerns for increased risk of disease transmission through the ocular route.

Patients wearing masks for extended periods may be more likely to experience these symptoms.

Eye protection and management of dryness and irritation is an important consideration for long-term mask users.

As society continually adapts to the everdeveloping circumstances surrounding the coronavirus disease 2019 (COVID-19) pandemic, a new article of clothing has become part of our daily routine: the face mask. We wholeheartedly support the necessity of face masks for a safe reopening of communities; however, as with any intervention, there may be sequelae of 
regular mask use in the general population. Over recent weeks, we have become aware of potential effects on the eye specifically.

In our community and patient population, we have seen a marked increase in dry eye symptoms among regular mask users at multiple local clinics. This group includes individuals who have never previously suffered from dry eyes. Individuals using masks regularly for an extended duration appear more likely to show symptoms. This group includes the elderly, immunocompromised, and clinic staff who wear masks almost full-time.

We saw numerous individuals at our practice who were regular mask wearers, including both patients and staff. These individuals described a subjective worsening in symptoms assessed in the Ocular Surface Disease Index. Patients showed a deterioration in corneal staining, as well as a distinct increase in dryness reported by cataract patients on postoperative day 1 . The majority of individuals described an awareness of air blowing upward from the mask into their eyes. This increased airflow likely accelerates the evaporation of the tear film which, when continuous for hours or days, may result in ocular surface irritation or inflammation. In addition to air convection, other factors are also likely at play. Staff members using taped masks to prevent air convection toward the eyes also complained of corneal irritation. In these cases, we postulate that the tape adhering to the skin of the upper cheek may interfere with the normal excursion of the lower eyelid, possibly inducing mechanical ectropion with secondary lagophthalmos.

Discussion of prolonged mask use and its effects on the eye is absent from the literature, although irritation of the eye has been described in similar situations. Exposure keratopathy has been documented as a result of lagophthalmos, ectropion, or mechanical ventilation $[1,2]$. Devices that mechanically blow air around the face have also been found to affect the eye. One study showed an increase in dry eye symptoms with certain powered air-purifying respirators (PAPRs) [3]. Irritation and contact lens dryness were found in patients using chemical protection hoods that blow air across the inside of the face mask [4]. Continuous positive airway pressure (CPAP) masks may cause ocular surface irritation due to air leakage or regurgitation through the nasolacrimal system $[5,6]$. All of these studies suggest that increased air convection affects the eye; however, this process is not described in the context of face mask use.

Interestingly, some studies are also beginning to find dry eye symptoms in COVID-19positive patients $[7,8]$. While these articles suggest dry eye as a complication of the disease itself, we propose that these findings may be partially associated with mandatory, long-term mask use in these patients, rather than sole sequelae of COVID-19. The authors of another article briefly theorize that more frequent eye touching may increase virus transmission because of the uncomfortable feeling of air blowing from the face mask into the eyes [9].

While universal mask use in public is essential during the current pandemic to reduce disease transmission through the mouth and nose, the unprotected eye remains a vulnerable path of infection. This pathway may be further compromised by irritation from mask use. The tear film is an essential barrier against pathogenic invasion but may be compromised if mask use causes this barrier to evaporate more rapidly [10]. Discomfort from dry eyes may also increase eye rubbing and face touching behaviors, with attendant fomite transmission [9]. All of these factors together create an increased concern for ocular infections secondary to prolonged mask wear. This risk is particularly worrisome during the current pandemic due to a well-documented probability of the novel coronavirus spreading through contact with the eye $[8,10,11]$.

If our observations of mask-associated ocular dryness and irritation prove to be consistent in all mask wearers, patients and providers need to be aware of these potential ramifications. Lubricant eye drops and eye protection, such as goggles, should be used in conjunction with masks. Additional care should be taken by individuals using masks for extended periods and by patients with prior history of dry eye disease, recent ophthalmic surgery, or other surface inflammatory diseases, such as Sjogren syndrome. 
Masks with a pliable nose-wire should be used, with attention toward fitting the shape of the wire to prevent air being directed toward the eyes. Masks can also be taped at the top to impede upward airflow, but care should be taken to ensure that lower lid excursion is not inhibited. Patients experiencing dry eye symptoms from extended mask wear should take breaks every few hours to remove the mask, allow the eyes to recover, and reapply lubricant eye drops. Emollient eye drops may be the most effective in preventing symptoms by preserving tear film. Blinking exercises may also be beneficial.

With COVID-19 and accompanying face mask use likely projecting well into the future, eye dryness, irritation and keratopathy from mask wear may become a problem for a large percentage of the population. If present, this mask-associated ocular irritation raises concerns about eye health and increased risk of disease transmission in prolonged mask users. We invite our colleagues to take note of this possibility, educate patients on proactive eye care and protection, and encourage further observation of this issue.

This article is based on previously conducted studies and does not contain any studies with human participants or animals performed by any of the authors.

\section{ACKNOWLEDGEMENTS}

Funding. No funding or sponsorship was received for this study or publication of this article. The Rapid Service Fee was funded by the authors.

Authorship. All named authors meet the International Committee of Medical Journal Editors (ICMJE) criteria for authorship for this manuscript, take responsibility for the integrity of the work, and have given final approval to the version to be published.

Disclosures. Majid Moshirfar, William B West Jr, and Douglas P. Marx declare that they have nothing to disclose.
Compliance with Ethics Guidelines. This article is based on previously conducted studies and does not contain any studies with human participants or animals performed by any of the authors.

Open Access. This article is licensed under a Creative Commons Attribution-NonCommercial 4.0 International License, which permits any non-commercial use, sharing, adaptation, distribution and reproduction in any medium or format, as long as you give appropriate credit to the original author(s) and the source, provide a link to the Creative Commons licence, and indicate if changes were made. The images or other third party material in this article are included in the article's Creative Commons licence, unless indicated otherwise in a credit line to the material. If material is not included in the article's Creative Commons licence and your intended use is not permitted by statutory regulation or exceeds the permitted use, you will need to obtain permission directly from the copyright holder. To view a copy of this licence, visit http://creativecommons.org/licenses/by$\mathrm{nc} / 4.0 /$.

\section{REFERENCES}

1. Vallabhanath P, Carter SR. Ectropion and entropion. Curr Opin Ophthalmol. 2000;11:345-51.

2. Kousha O, Kousha Z, Paddle J. Exposure keratopathy: Incidence, risk factors and impact of protocolised care on exposure keratopathy in critically ill adults. J Crit Care. 2018;44:413-8.

3. Powell JB, Kim JH, Roberge RJ. Powered air-purifying respirator use in healthcare: effects on thermal sensations and comfort. J Occup Environ Hyg. 2017;14(12):947-54.

4. Dennis RJ, Miller RE 2nd, Peterson RD, Jackson WG Jr. Contact lens wear with the USAF protective integrated hood/mask chemical defense ensemble. Aviat Space Environ Med. 1992;63(7):565-71.

5. Salinas R, Puig M, Fry CL, Johnson DA, Kheirkhah A. Floppy eyelid syndrome: a comprehensive review. Ocul Surf. 2020;18:31-9. 
6. Singh NP, Walker RJE, Cowan F, Davidson AC, Roberts DN. Retrograde air escape via the nasolacrimal system. Ann Otol Rhinol Laryngol. 2014;123(5):321-4. 0003489414525924 . https://doi.org/10.1177/

7. Hong N, Yu W, Xia J, Shen Y, Yap M, Han W. Evaluation of ocular symptoms and tropism of SARS-CoV-2 in patients confirmed with COVID-19. Acta Ophthalmol. 2020. https://doi.org/10.1111/ aos. 14445 .

8. Wu P, Duan F, Luo C, Liu Q, Qu X, Liang L, et al. Characteristics of ocular findings of patients with coronavirus disease 2019 (COVID-19) in Hubei Province, China. JAMA Ophthalmol. 2020;138: 575-578.
9. Lazzarino AI. Rapid response to: face masks for the public during the covid-19 crisis. BMJ. 2020;369: m1435. https://www.bmj.com/content/369/bmj. $\mathrm{m} 1435 / \mathrm{rr}-40$.

10. Sun C, Wang Y, Liu G, Liu Z. Role of the eye in transmitting human coronavirus: what we know and what we do not know. Front Public Health. 2020;8:155. https://doi.org/10.3389/fpubh.2020. 00155/full.

11. Olivia Li J-P, Shun Chiu Lam D, Chen Y, Shu Wei Ting D. Novel coronavirus disease 2019 (COVID19): the importance of recognising possible early ocular manifestation and using protective eyewear. 2020;104(3). https://bjo.bmj.com/. Accessed 14 May 2020. 